\title{
Estrutura Profunda e Padrões de Representação Semântica
}

\author{
Telmo Correia Arrais
}

\section{1 .}

Os últimos doze anos têm-se mostrado fecundos quanto a publicações relacionadas com a "semântica gerativa". Se por meados da década de 60 tais publicações se caracterizaram pelo aspecto polêmico, já em fins dessa década esboçam uma fase de maior reflexão e elaboração, caminhando hoje para uma boa formalização e síntese, graças, sobretudo, à progressiva integração da lógica aos estudos semânticos.

O interesse pelo sentido - tão desprezado no quadro da linguística norteamericana anterior ao gerativismo advém de uma comprovação bastante simples: a do quanto é óbvio, para o falante de uma língua, que o significado é um elemento central e decisivo em sua atividade linguística. Mas, a partir do momento em que os gerativistas se dão conta deste fato, os problemas se levantam: Como considerar um nível tão fluido como o semântico? Em que parte da gramática se deve localizá-la e qual será seu papel? Qual será sua (possível) relação com o componente transformacional? Enfim, será a semântica gerativa propriamente uma "teoria do sentido"?

Para os gerativistas da "teoria padrão", tão fortemente centralizada na sintaxe, a solução foi tratar o nível semântico como um componente interpretativo. Preservava-se, dessa forma, a in- dependência e autonomia da sintaxe na estrutura profunda. A certa altura, porém, os gerativistas dão-se conta de que a distinção entre sintaxe e semântica era relativamente precária. Daí o surgimento de duas orientações teóricas: de um lado, a teoria interpretativa, que tenderá a manter a distinção entre sintaxe e semântica; de outro lado, a teoria da semântica profunda, que tenderá a apagar tal distinção, com noções de ordem sintático-semântica que acabam por constituir o princípio organizador do seu sistema. Esta última orientação, conseqüentemente, teve de reconsiderar alguns princípios teóricos do modelo transformacional, embora sem rompimento com a tradição gerativista ${ }^{(1)}$.

\section{2.}

A questão fundamental das posições teórico-críticas assumidas contra a teoria clássica diz respeito ao estatuto da estrutura profunda(2). Não se tratava,

(1) Para uma visão pormenorizada das idéias dos vários autores de ambas as correntes, consulte-se Michel Galmiche (1975), que faz um balanço crítico de tais orientações teóricas de modo bem abrangente.

(2) Chomsky (1972, p. 75-76) aponta a "obscuridade" e a "confusão" como os véus que cobrem este domínio, conforme se depreende desta passagem: "A good part of the critique and elabora- 
certamente, de pôr em causa a hipótese fundamental da concepção transformacionalista da gramática, segundo a qual a descrição linguística deve postular um nível subjacente, suficietemente simples, geral e universal, que pode ser posto em relação com o conjunto das frases de uma língua. Como bem mostra Charles Fillmore (1966, passim, 1968, p. 1719), o nível de estrutura profunda, tal como havia sido considerado até então, não correspondia às exigências de generalidade e universalidade: tratava-se, antes, de um modelo heterogêneo, onde noções relacionais (sintáticas) como "Sujeito" e "Objeto Direto" aparecem ao lado de noções semânticas como "Advérbio de modo", "Advérbio de tempo", etc. E Fillmore ressalta, notavelmente, que as primeiras têm um papel apenas secundário na caracterização das frases: a noção de sujeito, por exemplo, só intervém nas questões relativas à colocação dos constituintes na frase e à concordância gramatical do verbo em pessoa e número, ou seja, diz respeito de fato aos fenômenos próprios da estrutura de superfície. Além do mais, é impossível conferir às noções de Sujeito e Objeto qualquer pertinência semântica; em outras palavras: estas funções não têm um sentido constante.

Percebe-se, facilmente, a inadequação de uma teoria que considera este gênero de "estrutura profunda" como o nível destinado à interpretação semântica. Daí a necessidade de substituir tais noções por um aparelho conceptual mais ade-

tion of the standard theory in the past few years has focussed on the notion of deep structure and the relation of semantic representation to syntactic structure. This is quite natural. No area of linguistic theory is more veiled in obscurity and confusion, and it may be that fundamentally new ideas and insights will be needed for substantial progress to be made in bringing some order to this domain." quado. Este aparelho conceptual, variável de autor para autor, assenta na idéia básica de que só um nível de representação semântica é capaz de atingir o poder explicativo que se espera de um nível subjacente.

\section{1 .}

Faz-se necessário, neste ponto, explicar a noção de "representação semântica" e sua relação com a estrutura profunda. Não haverá, certamente, coincidência entre os vários autores quanto a tal noção, embora concordem quanto à visão das representações semânticas como compostas de conceitos universais, o que faz supor que elas sejam, em princípio, independentemente motivadas. Assim, para George Lakoff (1969-1971, p. 339-340), a representação semânticá RS compreende uma estrutura inicial $I_{1}$ (estrutura pós-lexical gerada por um componente categorial) e a indicação das Pressuposições, do Tópico e do Foco da frase. Daí, $\mathrm{RS}=\left(\mathrm{I}_{1} \mathrm{P}, \mathrm{T}\right.$, F, ... ) (3).

Já para James McCawley (1968, p. 138), a representação semântica das frases deve envolver não os simples "marcadores do tipo traço" mas antes "predicados" no sentido lógico-simbólico do termo. Para ele, a leitura mais comum da palavra homem não deve ser representada como um conjunto de marcadores [humano, macho, adulto] e sim como um conjunto de propriedades ('humano', 'macho' e 'adulto') que são predicadas a partir do ser ou indivíduo ao qual se pretende referir ${ }^{(4)}$.

(3) Lakoff desenvolve cada uma dessas noções, mas deixa em aberto, declaradamente, a questão da existência de outros elementos da representação semântica de que se deva dar conta.

(4) McCawley explica que emprega referir em conexão com o 'referente intencional' de um sintagma nominal, e não com seu 'referente real', ou seja, os indices correspondem a itens no quadro do universo mental do falante e não a coisas reais no universo. 
Por outro lado, o que caracteriza alguns dos trabalhos lingüísticos recentes é a tendência a considerar a estrutura mais profunda da frase como a representação isomórfica de uma situação extra-ingüística referida pelo locutor. Qualquer situação extra-lingüística se caracteriza por relações entre processo e substâncias, relações essas que se observam quer na natureza, quer na vida social, quer em nossa atividade psíquica. Assim, a substância pode representar o papel de agente de um processo, de origem ou de causa de uma ação, de afetado por um evento, de instrumento de uma ação, de destinatário de um processo, de objeto visado por uma ação, etc. $\mathrm{O}$ conjunto das relações extralinguísticas existentes entre processo e substâncias constitui a estrutura da referência de uma dada situação extra-linguística. Processo e substâncias são representados, na estrutura profunda das frases de uma língua, por unidades linguísticas apropriadas - por semantemas verbais e por semantemas nominais, respectivamente. Como afirma M. Kubik (1972, p. 20), "as relações extra-lingüísticas entre o processo e as substâncias se transformam, no nível da estrutura profunda da frase, em relações semânticas entre os semantemas nominais e o semantema verbal". Estas relações semânticas, entretanto, não refletem propriamente as relações extra-lingüísticas entre os elementos; antes "representam o resultado de um arranjo destas relações na consciência do homem por intermédio da língua" (idem, p. 20).

Os semantemas nominais — mais comumente tratados como sintagmas nominais -, aos quais têm sido propostos vários termos para identificá-los em estrutura profunda (actantes segundo Greimas, casos segundo Fillmore, substantemas segundo Kubik), são definidos e classificados de acordo com o caráter de suas relações semânticas com o semantema ou sintagma verbal. Na lite- ratura linguiística atinente, distinguem-se as seguintes categorias para os sintagmas nominais: agente (instigador do processo verbal), objeto (ser visado pela ação verbal), instrumento (estímulo ou causa física imediata de um evento), receptor (ser que recebe ou sofre as consequiências da ação), locativo (entidade na qual a ação é localizada), destinatário (ser ao qual a ação é destinada), etc. ${ }^{(5)}$. Será esta a base com que Fillmore esboçará uma "gramática dos casos", cuja estrutura subjacente é uma representação semântica da relação entre verbo e sintagmas nominais, estes providos de etiquetas semânticas do tipo acima apontado.

O ponto comum aos diversos autores é que se deve conceber um sistema de representação no qual o conteúdo semântico dos nomes e verbos se origina no exterior das frases em que são utilizados. Em outros termos: devem receber um modo de representação que dê conta de sua função semântica de referência, tanto real como intencional.

Pensamos, entretanto, que tal representação seria incompleta se se considerasse apenas o conteúdo semântico original exterior à frase. Nomes e verbos vêm a adquirir um conteúdo semântico complementar relacional, resultante das relações específicas que mantêm uns com os outros no interior da frase em que são inseridos.

\section{2}

Para nós, o que acabamos de expor em 2.1 como "representação semântica", resultado do que se encontra correntemente nos trabalhos linguísticos gerativistas destes últimos anos, parece sem dúvida bastante heterogêneo. Fala-se, de um lado, em relações extra-lingüísticas

(5) Cf. Charles Fillmore (1968, p. 24-25; 1969, p. 115-116) e Don Lee Fred Nilsen (1972, passim). 
entre processo e substâncias (o que constitui, portanto, a estrutura da referência) e, de outro lado, em categorias atribuídas a sintagmas nominais de acordo com o caráter de suas relações semânticas com o verbo (o que evidencia, certamente, uma estruturação linguística de natureza sintático-semântica). Percebe-se, mesmo, o valor nocional variável com que cada autor emprega a expressão "representação semântica", adquirindo tal expressão uma gama de significações relativamente grande ${ }^{(6)}$.

De nossa parte, cremos que o problema está em não se distinguirem diferentes padrões de representação semântica na estrutura mais profunda das frases da língua, que não deve ser confundida com a estrutura profunda sintática do modelo clássico. Esta última deverá reduzir-se, pois, a uma estrutura intermediária, constituída de um conjunto de regras sintagmáticas e de um componente transformacional, cujas regras permitem derivar estruturas sintático-semânticas em estruturas de superfície. Fica implícito, portanto, que a nosso ver não é válido postular a existência de um só tipo de representação na estrutura profunda semântica; admitimos, antes, a existência de pelo menos três padrões nessa estrutura, cuja diferença é marcada pela presença de regras formativas diversas em cada padrão, as quais se apresentam em diferentes graus de complexidade.

O primeiro padrão, a que chamaremos "referencial-semântico", é caracterizado por "regras de formação léxica"; dele trataremos no item 3. O segundo padrão, caracterizado por processos for-

(6) O mesmo ocorre com a expressão "estrutura profunda", que para alguns corresponde ao componente sintático da frase, enquanto para outros corresponde ao componente semântico ou sintático-semântico. mativos a que propomos o nome genérico de "formações por modalização", será chamado "lógico-semântico"; dele trataremos no item 4. Enfim, ao terceiro padrão nos referiremos como o "sintático-semântico", caracterizado por processos formativos a que damos o nome geral de "formações por concatenação"; este será tratado no item 5. Reservamos o item 6 para tratar do problema da equivalência semântica de frases, com relação a esses três padrões.

\section{3.}

O padrão "referencial-semântico", caracterizado por regras de formação léxica, é o da representação dos itens lexicais por conjuntos de propriedades inerentes, e estas em concordância com as características peculiares do objeto ou processo referido, tal como é "mentado" pelo falante-ouvinte. Isto corresponde, pois, a considerá-lo primeiramente como o padrão em que se procede à análise do significado das palavras - tomadas individualmente — por definições de caráter externo. Definições externas são, pois, as que relacionam itens lexicais de uma língua com entidades fora do próprio sistema linguiístico. Este tipo de análise do significado das palavras tem tido especialmente dois tratamentos: o primeiro é baseado nas regras semânticas (ou "meaning postulates”) de Carnap (1956, p. 222-9), o segundo nos componentes semânticos em que os significados lexicais são decompostos. Eis os exemplos que ilustram o tratamento baseado em regras semânticas:

\section{(1) (a) homem $\rightarrow$ macho \\ (b) mulher $\rightarrow$ fêmea}

Uma regra como (1a) diz que homem implica macho ou, ou que dá na mesma, que sentenças como Um homem é macho ou Se $x$ é um homem, então $x$ é macho são analíticas 
As regras semânticas podem também envolver partículas lógicas como 'e', 'ou', 'não', etc.:

(2) (a) homem $\rightarrow$ macho e adulto

(b) mulher $\rightarrow$ fêmea e adulto

(c) fêmea $\rightarrow$ não macho

(d) criança $\rightarrow$ não adulto

(e) homem ou mulher ou criança $\rightarrow$ humano

Assim, o significado de um item lexical de uma língua é definido implicita- mente pelo conjunto de todos os postulados significativos que neie ocorrem.

$\mathrm{O}$ segundo tratamento mencionado, o da análise componencial, define o significado de um item lexical explicitamente em termos de componentes semânticos. Mas tais componentes não devem ser tomados como parte do vocabulário da própria língua, e sim como elementos teóricos, requeridos a fim de descrever as relações semânticas entre os elementos lexicais de uma língua. Estes componentes são também conectados através de partículas lógicas, como se depreende dos seguintes exemplos:

(3) (a) homem: ANIMADO e HUMANO e MACHO e ADULTO

(b) mulher: ANIMADO e HUMANO e FEMEA e ADULTO

(c) potro: ANIMADO e não HUMANO e EQÜINO E MAC:̃ e não ADULTO

Na verdade, tal sistema de definições de itens lexicais compreende regras de implicação que acarretam à descrição grande redundância. Eis algumas regras depreendidas dos exemplos acima:

(4) HUMANO $\rightarrow$ ANIMADO

MACHO ou FEMEA $\rightarrow$ ANIMADO

MACHO $\rightarrow$ não FÊMEA

FÊMEA $\rightarrow$ não MACHO

EQÜINO $\rightarrow$ não HUMANO mas ANIMADO

Daí podermos ter $(5 \mathrm{a})$ como uma simplificação da forma plena (5b), expressando a primeira as generalizações mais relevantes sobre a estrutura semântica do vocabulário descrito:

\section{(5) (a) homem: HUMANO e MACHO e ADULTO \\ (b) homem: ANIMADO e HUMANO e MACHO e não FÊMEA e ADULTO}

Do confronto dos dois tipos de tratamento acima expostos, conclui-se que há certamente uma grande relação entre ambos. Assim, uma análise componencial do tipo ilustrado em (3) e (5) pode ser convertida em um sistema de regras semânticas e, ao contrário, um sistema de regras semânticas como o ilustrado em (1) e (2) pode ser convertido em um sistema componencial. Contudo, observe-se que o estatuto de elementos como macho em (1) e (2) não é o mesmo 
que MACHO em (3) e (5): no primeiro caso é entendido como pertencente à língua descrita, enquanto no segundo caso são elementos puramente teóricos. De qualquer modo, consideramos ambas as análises como formalmente equivalentes, não havendo motivos suficientes para quebrar lanças por uma ou por outra.

Outra comprovação a que nos levam tais análises é a da existência de relações do significado entre os diferentes itens lexicais, ou seja, os itens lexicais acabam por poder ser descritos através de definições internas. De um modo mais explícito, queremos dizer que, se o significado de uma palavra é um complexo de componentes (ou traços, ou marcadores) semânticos, há relações entre as propriedades semânticas dos diversos itens que podem ser definidas. Assim, homem e mulher são 'antônimos' porque o primeiro item lexical tem um componente $\mathrm{C}$ onde o segundo tem C', sendo C e C' componentes mutuamente exclusivos; celibatário e solteiro são 'sinônimos' porque apresentam os mesmos componentes conectados pelas mesmas partículas lógicas, etc.

\section{1.}

No padrão de representação lógico-semântica, as formações por modalização são entendidas como procedimentos lógico-gramaticais que conduzem a esquemas lingüísticos determinados, empregados para indicar ou identificar "coisas" (substâncias) ou "processos". Em síntese, trata-se de uma estrutura abstrata em função da qual se podem conceber os esquemas lingüísticos que têm a função de identificar e os que têm a função de predicar. Os primeiros devem ser representados na estrutura lógico-semântica por expressões quantificadas do tipo argumento, os últimos serão representados como predicados lógicos, a que reservamos o nome de predicadores. Assim, com os termos predicador e argumento queremos caracterizar, neste nível, respectivamente o "processo" e a "substância".

A frase é pois aqui vista como uma unidade estruturada na base de um predicador e pelo menos um argumento, ambos determinados por formadores ou expoentes lingüísticos de diferentes tipos. Está claro, dessa forma, que os símbolos categoriais que vão representar a estrutura lógico-semântica profunda não deverão conter a noção de "classes de palavras" (N, V, Adv, Art) ou de "constituintes imediatos" (SN, SV, SA). Os símbolos categoriais deverão ser representações de classes semânticas reais ou propriedades que atravessam as áreas cobertas pelas tradicionais classes de palavras.

Há, portanto, a possibilidade de representar simbolicamente a estrutura lógico-semântica da frase como uma proposição de dois elementos mínimos: $\mathbf{P r}+\mathbf{A r g}_{\mathrm{n}}$, ou seja, um predicador e um número variável de argumentos, nunca inferior a 1. Desta forma, não há, na estrutura mais profunda, proposições reduzidas ao predicador ${ }^{(7)}$, e sim proposições com argumento implicado no predicador, por um processo transformacional comum a muitas línguas. Assim, em chove (Ingl. it's raining, Fr. il pluit, Esp. llueve, It. piove) há um argumento implicado no predicador, como uma declaração que se faz sobre o tempo ${ }^{(8)}$.

\subsection{1.}

Irena Bellert (1969) estudou os tipos de argumentos depreensíveis numa es-

(7) Trata-se, na superfície, das tradicionais "orações de verbo intransitivo sem sujeito".

(8) Os "casualistas", por exemplo, explicam tais construções como um verbo + um caso nocional agentivo, transformado em zero numa asserção sobre o tempo. (Cf. Ivan Poldauf, 1970, p. 124). 
trutura lógico-semântica, tendo chegado a três tipos. $\mathrm{O}$ argumento tipo-1 corresponde ao que aparece em sentenças em que o locutor identifica tão somente um "objeto", e lhe atribui um predicado. As frases (6)-(9) exemplificam as ocorrências desse tipo de argumento:

(6) Mário casou-se.

(7) O rapaz casou-se.

(8) Mário foi horrivelmente acidentado.

(9) Aconteceu um horrível acidente com o rapaz ${ }^{(9)}$.

É plausível supor que, para cada sentença com uma referência particular, é possível encontrar uma paráfrase em que ocorrerão tantos índices lingüísticos quanto o número de "seres" que se supõe serem identificáveis no momento em que uma sentença é pronunciada num processo normal de comunicação. Assim, consideramos a frase (7) como paráfrase de (6) e a frase (9) como paráfrase de (8). $\mathrm{O}$ emitente de qualquer uma dessas mensagens (consideremo-las como mensagens intencionais, e não como meros exemplos) tenciona identificar tão somente um indivíduo (o qual deverá ser identificado pelo destinatário da mensagem, de acordo com o contexto situacional), ao qual aplica o predicado (casou-se ou foi horrivelmente acidentado). Certamente, se não forem satisfeitas as condições de identificação pelo contexto situacional, o destinatário sem dúvida reagirá, para compreender integralmente a oração, perguntando: “Qual Mário?” ou “Que rapaz?”. Dessa forma, um índice linguístico pode estar acompanhado de um esclarecimento mais detalhado, cuja realização será do tipo:

(10) Mário, o filho do compadre, casou-se.

(9) Note-se que o argumento não coincide necessariamente com os termos que ocupam a posição do sujeito gramatical.
(11) Meu sobrinho Mário casou-se.

(12) Aconteceu um horrível acidente com o rapaz que mora na minha casa.

Enfim, tal tipo de argumento pode ser chamado "operador descritivo".

\subsection{2.}

O argumento tipo-2, de acordo com Irena Beillert, corresponde àqueles que servem para indicar todos os "objetos" ou "indivíduos" aos quais se aplica um predicado lógico. São reconhecidos na estrutura de superfície por quantificadores como "todos", "cada" e outros tipos de formadores. As frases (13)-(16) são exemplos em que ocorre tal tipo de argumento:

(13) Todos os membros do partido aprovaram o nome do candidato.

(14) Cada empregado deve ter scu próprio seguro.

(15) Os alunos podem matricular-se até fevereiro.

(16) Meus pais são jovens.

Em vista dos exemplos acima, a primeira observação a ser feita diz respeito à possibilidade de deslocamento do quantificador na superfície, podendo mesmo aparecer como determinante do verbo. Assim, o exemplo (17) será uma perfeita paráfrase de (13), com argu-mentos de mesmíssimo valor:

(17) Os membros do partido aprovaram unanimemente o nome do candidato.

Observe-se, ainda, que o argumento da frase (16) é do tipo-2 porque tem um valor distributivo, pois a juventude se aplica a cada membro individual referido pela expressão descritiva "pais": Meu pai é jovem, Minha mãe é jovem. O exemplo (16) não pode ser confundido com o exemplo (18): 
(18) Meus pais compraram uma casa.

Neste, o índice descritivo "meus pais" é representado como um argumento do tipo-1, pois tem um valor único, por meio do qual se identifica tão somente um objeto, ou seja, um grupo de indivíduos tomados como um todo.

Os exemplos (15)-(16) evidenciam, por outro lado, que não há necessariamente a presença de um quantificador explícito na estrutura de superfície. É a interpretação do valor subjacente à expressão do argumento que permite depreender a referência à totalidade. $\mathrm{E}$ é essa mesma interpretação do valor subjacente que deve ser levada em conta quando da análise de "aparentes" operadores descritivos (tipo-1), como em (19)-(20):

(19) 0 homem é mortal.

(20) 0 rato pertence à família dos roedores.

Por certo, subjacentemente às expressões "o homem" e "o rato" nos exemplos acima, ocorrem operadores que indicam a totalidade: "todos os homens são mortais"; "todos os ratos pertencem à família dos roedores". Mas observe-se que tal interpretação se dá em função do predicado lógico aplicado ao argumento. A mesma interpretação não seria possível para o argumento do exemplo (21):

(21) O rato escondeu-se atrás da geladeira.

Ao argumento tipo-2 podemos chamá-lo "operador total".

\subsection{3.}

Finalmente, o tipo-3, tal como foi caracterizado por Irena Bellert, corresponde à determinação do argumento também por quantificadores, mas de outra espécie. Estes são representados, na estrutura de superfície da frase portuguesa, por numerais, pronomes indefinidos (não todos) e artigo indefinido (sete jovens, muitos estudantes, alguns professores, poucas pessoas, um colega). O argumento tipo-3 é usado, portanto, para indicar apenas um certo número de "indivíduos" ou "coisas", de quantidade definida ou indefinida.

A este tipo de argumento podemos pois chamá-lo "operador múltiplo-parcial", que pode ser do sub-tipo quântico-determinado, como em:

(22) Cinco pessoas estiveram hoje aqui.

(23) Um menino chorava copiosamente.

ou do sub-tipo quântico-indeterminado, como em:

(24) Poucas pessoas estiveram hoje aqui.

(25) Vários meninos choravam copiosamente.

Nas situações concretas do discurso, entretanto, argumentos do sub-tipo quântico-indeterminado podem estar acompanhados de uma expressão que explicite o número preciso, a qual neutralizará o valor quântico-indeterminado do argumento, como mostra o exemplo (26):

(26) Poucas pessoas, exatamente cinco, estiveram hoje aqui.

\subsection{1.}

É também possível (e, certamente, desejável) estudarem-se os tipos de predicadores depreensíveis no padrão lógico-semântico. Uma primeira visão da generalidade dos predicadores haveria de levar-nos a uma distinção entre duas grandes classes: a dos descritivos e a 
dos atributivos. Os descritivos seriam aqueles que indicam ação, movimento, processo psicológico, etc., relativamente a um argumento. Os atributivos seriam os que indicam propriedades, qualidades ou estados relativamente a um dado argumento.

Os exemplos (27)-(29) ilustram as ocorrências com predicadores descritivos:

(27) O herói lutou bravamente.

(28) Todos os cachorros correm atrás de gato.

(29) Alguns alunos pensavam com propriedade.

Os exemplos (30)-(33) ilustram as ocorrências com predicadores atributivos:

(30) Aquele rapaz tem valor.

(31) Algumas meninas eram simpáticas.

(32) A Terra parece redonda.

(33) Todos os marginais estão presos.

Percebe-se claramente a diferença formal entre os dois tipos de predica.dores: o segundo é marcado pela presença de um formador atributivo, representado em português pelos verbos copulativos, enquanto o primeiro não tem tal marca.

\subsection{2.}

Um papel semântico importante é desempenhado pelo formador negativo 'não', determinante do predicador (10). Assim, nas frases contraditórias, a adição do formador negativo transforma-as em tautologias. Vejamos alguns exemplos:

(10) A análise desse e de outros formadores é desenvolvida por Geoffrey Leech (1969, p. 44-59).
(34) (a) Estes meninos são adultos. (contradição)

(b) Estes meninos não são adultos. (tautologia)

(35) (a) O irmão mais velho de Pedro é mais novo que Pedro. (contradição)

(b) $\mathrm{O}$ irmão mais velho de Pedro não é mais novo que Pedro (tautologia)

Inversamente, a adição de um formador negativo a uma frase tautológica acarreta uma contradição. Assim:

(36) (a) Este menino é uma criança. (tautologia)

(b) Este menino não é uma criança. (contradição)

(37) (a) Os fiatelistas colecionam selos. (tautologia)

(b) Os filatelistas não colecionam selos. (contradição)

\subsection{3.}

Pode-se afirmar, entretanto, que as características dos predicadores descritas nos sub-itens acima em nada afetam a seleção deste ou daquele tipo de argumento. Mas, a presença de propriedades semânticas particulares nos predicadores, como as relacionadas ao tempo, espaço, duração do processo, etc., pode ser decisiva quanto à seleção ou restrição deste ou daquele tipo. Assim, algumas atividades são vistas como necessariamente prolongadas no tempo, outras não; este contraste é normalmente apresentado em termos de processo "continuativo" e 
processo "momentâneo", respectivamente (11). Por exemplo, dormir, é um predicador continuativo, acordar é momentâneo. Uma prolongada atividade, ou estado, ocupa necessariamente uma porção do tempo; daí ser possível determinar um verbo continuativo com um expoente que precise a duração. Faz sentido, portanto, o que se exprime em (38), mas não o que se exprime em (39):

(38) Ele dormiu $\left\{\begin{array}{l}\text { por três dias } \\ \text { até sábado }\end{array}\right\}$
$(39) *$ Ele acordou $\left\{\begin{array}{l}\text { por três dias } \\ \text { até sábado }\end{array}\right\}$

Por outro lado, a forma negativa de um verbo momentâneo pode identificar um estado contínuo, admitindo, pois, a construção com tal tipo de expoente. Daí fazer sentido a frase (40):

(40) Ele não acordou \{ $\left\{\begin{array}{l}\text { por três dias } \\ \text { até sábado }\end{array}\right\}$

Observe-se, entretanto, que, se a expressão complemento de um predicador momentâneo for representada por um operador múltiplo-parcial, do sub-tipo quântico-indeterminado, tal predicador adquirirá um valor "iterativo", identificando um processo que é repetido em espaços de tempo. Assim, acordar representa, no exemplo (41), um valor iterativo:

(41) Ele acordou $\left\{\begin{array}{l}\text { alguns dias } \\ \text { vários sábados }\end{array}\right\}$

Já os predicadores tipicamente iterativos, como esmurrar, poderão ser acompanhados de operador descritivo mais

\footnotetext{
(11) Cf., por exemplo, Charles Fillmore (1969, p. 112 e segs.).

(12) A anteposição do asterisco à frase indica sua agramaticalidade.
}

um expoente que especifique a duração, como é o caso do exemplo (42):

(42) Ele esmurrou o adversário até o $8^{\circ}$ assalto.

Com relação ao valor iterativo que podem apresentar os predicadores momentâneos, uma restrição deve ser feita: se $o$ predicador momentâneo indicar "mudança de estado", ele não poderá ser usado iterativamente quando um objeto específico ("operador descritivo") está envolvido, como em (43):

$$
\begin{aligned}
& \text { (43) * Ele quebrou o vaso até as } 5 \\
& \mathrm{~h} \text { da tarde. }
\end{aligned}
$$

Mas se estiver tal predicador seguido de um argumento tipo-2 ou tipo-3 ("operador total" ou "operador múltiplo-parcial"), então poderá ser empregado iterativamente, como em (44)-(45):

(44) Ele quebrou todos os vasos até as $5 \mathrm{~h}$ da tarde

(45) Ele quebrou vários vasos até as $5 \mathrm{~h}$ da tarde.

Enfim, com relação ao emprego do "operador total" nesta construção, cabe a seguinte nota: dada a agramaticalidade do uso do quantificador cada nesse tipo de frase, como mostra o exemplo (46), seu valor semântico será expresso, na estrutura de superfície, através do desdobramento sintático do argumento, como bem ilustra o exemplo (47):

(46) * Ele quebrou cada vaso até as $5 \mathrm{~h}$ da tarde.

(47) Ele quebrou vaso por vaso até as $5 \mathrm{~h}$ da tarde.

\section{4.}

Há, ainda, a possibilidade de caracterizar os predicadores de acordo com o número de argumentos que admitem 
Conforme já assinalamos no item 4.1., toda construção de tipo lógico-semântico se dá na base de uma relação mínima entre um Argumento e um Predicador. Mas deixamos entrever que podemos ter, numa proposição, dois ou mais Argumentos. Daí a fórmula de proposição sugerida: $\mathbf{P r}+\mathbf{A r g}_{\mathrm{n}}$, em que $\mathbf{n}=\mathbf{1}$. Há, não obstante, um limite teórico de argumentos. Em português, por exemplo, podemos ter verbos de 1 , de 2 , de 3 e até mesmo de 4 argumentos, respectivamente ilustrados nas frases abaixo:

(48) Pedro caiu.

(49) Pedro comprou tecidos.

(50) Pedro ofereceu alguns livros à namorada.

(51) Pedro comprou do João um livro para a Clélia (13).

Entretanto, muitos predicadores são flexíveis quanto ao número de argumentos, como comprovam os dois exemplos acima com o predicador comprar. Também com quebrar, afundar, incendiar, etc., podemos ter, por exemplo, os seguintes tipos de concatenação com argumentos:

(13) Os argumentos, sintaticamente concatenados em funções diversas com o predicador, apresentam-se em número finito. É ilusório pensar-se que, com argumentos em desempenho de uma mesma função, pode ter-se um número ilimitado. Assim, a frase

(52) Pedro comprou uma borracha, dois lápis, três livros, alguns cadernos, ...

é tão somente o resultado na superfície de uma transformação por supressão e conseqüente coordenação dos elementos de função idêntica. Em profundidade, teríamos:

(a) Pedro comprou uma borracha.

(b) Pedro comprou dois lápis. Etc.
(53) (a) Mário quebrou a janela com uma pedra.

(b) Uma pedra quebrou a janela.

(c) A janela quebrou.

(54) (a) Os inimigos afundaram o navio com um tiro de canhão.

(b) Um tiro de canhão afundou o navio.

(c) O navio afundou.

(55) (a) Um rapaz incendiou o depósito com um cigarro aceso.

(b) Um cigarro aceso incendiou o depósito.

(c) O depósito incendiou.

5.1.

A exemplificação acima, como todo o item 4.4., serve-nos como ponte para a apresentação do terceiro padrão depreendido na estrutura profunda, o "sintático-semântico". Como vimos, este padrão se caracteriza por processos formativos a que propusemos o nome geral de "formações por concatenação". Já chamamos a atenção, no item 2.1., para o caráter das relações semânticas dos sintagmas nominais (argumentos do $2^{\circ}$ ? padrão) com o verbo ou sintagma verbal (predicador do $2^{\circ}$ padrão). Ora, na descrição lingüística do padrão sintático-semântico deve-se, portanto, proceder a abstrações do papel específico desempenhado por cada sintagma nominal de uma dada proposição. Esta tarefa conduzirá à observação de que os papéis desempenhados por tais sintagmas estão em estreita relação com o próprio caráter semântico dos verbos com que se associam. A "formação por concatenação" corresponde, pois, a constituir uma proposição em que se estabelece uma interdependência semântica e sintática entre o verbo e os sintagmas nominais, cuja escolha a opcionalidade são determinadas pelo próprio verbo. É o 
que nos evidenciam os exemplos (53)(55) acima arrolados. Se conferirmos a cada argumento (Sintagma Nominal) um rótulo "casual" — de acordo com a teoria de Fillmore - em conformidade com o papel semântico que desempenhe (Agentivo para instigador do processo verbal; Objetivo para objeto ou coisa atingida pelo processo verbal; Instrumental para nome de força ou objeto inanimado causalmente envolvido na ação expressa pelo verbo, etc.), teremos determinado o traço de construção característico de qualquer um daqueles três verbos, isto é, a forma como se concatenam, sintática e semânticamente, os argumentos passíveis de ocorrer com aquele tipo de predicador. Seria o seguinte o traço de construção: [

$\mathrm{O}$ (I) (A) ]. Isto significa que tal tipo de verbo deve ter um caso Objetivo, e pode ter facultativamente um caso Instrumental (I) e um caso Agentivo (A). Em outros termos: predicadores como quebrar, afundar ou incendiar são verbos que se concatenam com três casos $(\mathrm{Ob}$ jetivo, Instrumental e Agentivo) ou com dois casos (Objetivo e Instrumental) ou com um caso (Objetivo) (14).

(14) Convém não confundir a concatenação em estrutura profunda com a concatenação em estrutura de superfície, esta também passível de descrição. É certo, entretanto, que a concatenação em estrutura de superfície tem grande dependência da concatenação em estrutura profunda, uma vez que dela deriva. Pode-se observar, assim, na construção em que ocorre o Agentivo, que este é automaticamente o Sujeito na estrutura de superfície; na construção que não tem Agentivo e sim Instrumental, este assume a posição de Sujeito na superfície; enfim, na construção em que não há Agentivo ou Instrumental, o Objetivo torna-se automaticamente. o Sujeito na superfície (Cf. Fillmore, 1968, p. 33).
As descrições lingüísticas deste padrão estrutural deverão conduzir a um conjunto finito de casos universais que estão presentes em cada língua particular. Não se trata de investigar os "casos", portanto, como "funções semânticas de afixos flexionais nos nomes ou as relações de dependência que se mantêm entre afixos nominais específicos e propriedades léxico-gramaticais de elementos vizinhos" (Fillmore, 1968, p. 2). Enfim, o "caso" não é examinado como uma categoria da estrutura de superfície, tal como é apresentado nas gramáticas do grego e do latim (caso nominativo, genitivo, acusativo, ablativo, etc.) e sim como um estudo dos importantes e formais universais lingüísticos.

Dessa forma, os "casos" constituem verdadeiras "categorias encobertas", na medida em que se apresentam como propriedades semântico-gramaticais desprovidas de realizações morfêmicas manifestas, mas que "têm uma realidade que pode ser observada na base de restrições : seletivas e possibilidades transformacionais" (Fillmore, 1968, p. 3). Daí serem vistas as "relações casuais" como relações sintáticas, semanticamente relevantes, envolvendo os nomes e as estruturas que os contêm, e formando um conjunto finito específico.

\section{2 .}

A análise das relações casuais entre os sintagmas nominais e o sintagma verbal na estrutura profunda permite descobrir o modelo único subjacente a toda série de frases superficialmente diferentes. Tomemos, por exemplo, as frases (56)-(59) com estruturas sintáticas superficiais específicas:

(56) Os meninos começaram a correr por um caminho sem fim.

(57) Acabou de correr mar adentro.

(58) Bandos de camponeses haviam corrido as ruas da cidade. 
(59) As ruas da cidade haviam sido corridas por bandos de camponeses.

As diferenças entre estas quatro frases são patentes. Vejamos algumas: quanto ao sujeito, ora está claramente expresso, ora oculto; além disso, se ele é ativo nas frases (56), (57) e (58), já na frase (59) não o será; o verbo auxiliar varia de exemplo para exemplo, com conseqüente variação do valor aspectual; também se observa a variação entre os tempos pretérito perfeito e pretérito mais-que-perfeito; o complemento é preposicionado numas frases e diretamente relacionado ao verbo noutras, com conseqüente variação de funções: complemento adverbial, complemento direto e complemento agente da passiva; aliás, a própria voz verbal se manifesta como ativa nas frases (56)(58), e como passiva na frase (59).

Embora outras diferenças mais possam ser apontadas na estrutura de superfície, a análise das relações semânticas entre os sintagmas nominais e o verbo, em estrutura profunda, há de mostrar a identidade estrutural dessas quatro frases. Assim, em todas elas há um sintagma nominal (não imporia se expresso ou se oculto na estrutura de superfície) que funciona como agente - instigador que é da ação verbal; há outro sintagma nominal que assinala a direção extensional do verbo - funcionando pois como direcional. Por isso, podemos falar de uma arquifrase subjacente a essas quatro frases realizadas, cuja estrutura pode ser assim representada: $(\mathrm{SNag}+\mathrm{SV}+\mathrm{SNdi})$ ou [

$\mathrm{Di}, \mathrm{Ag}$ ].

6.

Uma vez analisados os três padrões de representação semântica por nós propostos, cabe uma abordagem final do problema da equivalência semântica entre frases. $\mathrm{O}$ problema, que pode ser colocado a partir das frases (56)-(59) acima, é o seguinte: se apontamos uma mesma arquifrase subjacente às quatro frases, quer isso dizer que elas são semanticamente equivalentes? A resposta correta deverá ser esta: as duas primeiras, (56) e (57), são semanticamente equivalentes quanto ao terceiro padrão (sintático-semântico), mas não quanto aos demais; já as duas últimas, (58) e (59), são semanticamente equivalentes com relação a todos os padrões.

Assim, a equivalência semântica pode ser relativa a um padrão particular, com exclusão dos demais, ou simultaneamente a dois padrões, ou, de forma total, aos três padrões. Vejamos, inicialmente, estes dois exemplos:

(60) Aquele celibatário coleciona selos.

(61) Alguns solteiros são filatelistas.

Com respeito a estas duas frases, pode-se dizer que são semanticamente equivalentes relativamente ao padrão referencial-semântico, mas não aos demais. De fato, em relação ao primeiro padrão, uma vez consideradas as regras de implicação (p. ex., filatelista $\rightarrow$ colecionar selos), vamos encontrar os mesmos componentes semânticos nos termos correspondentes de uma frase à outra. Mas o mesmo não se pode dizer com relação ao segundo e terceiro padrões. Assim, na análise do padrão lógico-semântico, logo deparamos com um "operador descritivo" em (60) e um "operador múltiplo-parcial" em (61), além de se apresentarem ambas as frases com um número diferente de argumentos; já na análise do padrão sintático-semântico, percebe-se não ser o mesmo o papel representado pelos sintagmas nominais nos dois exemplos: basta notar o papel ativo de celibatário em (60), em contraposição ao papel estático-descritivo de 
solteiros em (61), além de um "caso" a mais representado em (60).

Pensemos, agora, nas duas seguintes frases:

(62) Todos os alunos aclamaram o professor.

(63) Todos os funcionários censuraram o diretor.

Quanto a estas duas frases, pode-se dizer que não apresentam qualquer equivalência semântica com relação ao primeiro padrão, já que os itens lexicais correspondentes de uma à outra apresentam pouquíssimos componentes semânticos em comum; mas são semânticamente equivalentes quanto aos padrões segundo e terceiro, já que os mesmos tipos de operadores, e predicadores também de mesmo tipo, aparecem em ambas, desempenhando os Sintagmas Nominais correspondentes o mesmo papel semântico com relação aos verbos, que aliás apresentam o mesmo traço de construção.

Enfim, observemos as duas frases abaixo:

(64) Alguns funcionários censuraram o colega.

(65) Alguns empregados reprovaram o companheiro.

Nelas se nota, primeiramente, uma correspondência semântica termo a termo, de tal forma que os itens lexicais que ocupam a mesma posição nas duas frases apresentam os mesmos componentes semânticos; podemos dizer, por isso, que são sinônimos. Os operadores são também correspondentemente do mesmo tipo ("múltiplos-parciais" e "descritivos"), apresentando os verbos as mesmas características semânticas ("descritivos", "continuativos", etc.). Enfim, o traço de construção é o mesmo para ambos os verbos, que selecionam "casos" idênticos. Pode-se dizer, portanto, que estamos diante de uma equivalência semântica total, uma vez que se dá com relação aos três padrões subjacentes.

7.

Em síntese, eis os pontos fundamentais de nossa análise:

a) Só um nível de representação semântica tem o poder explicativo que se espera de uma teoria lingüística.

b) $\mathrm{Na}$ representação semântica de uma frase, deve considerar-se o conteúdo semântico original exterior à frase e o conteúdo semântico relacional, resultante das relações específicas que os nomes e os verbos mantêm entre si no interior da frase.

c) A estrutura sintática do modelo gerativista padrão reduz-se a uma estrutura intermediária, entre a estrutura profunda (semântica) e a estrutura de superfície (morfofonológica), sendo constituída de regras sintagmáticas e de regras transformacionais (V. gráfico representativo).

d) $\mathrm{Na}$ estrutura profunda distinguem-se três diferentes padrões de representação semântica, caracterizados pela presença de regras formativas com diferentes graus de complexidade (V. gráfico representativo).

e) $\mathrm{Da}$ semelhança das frases da língua, com vistas a qualquer um desses padrões, resulta o problema da equivalência semântica, que tanto pode ser relativa a um, a dois ou aos três padrões, isto é, tanto pode ser parcial como total. 


\section{Gráfico Representativo:}

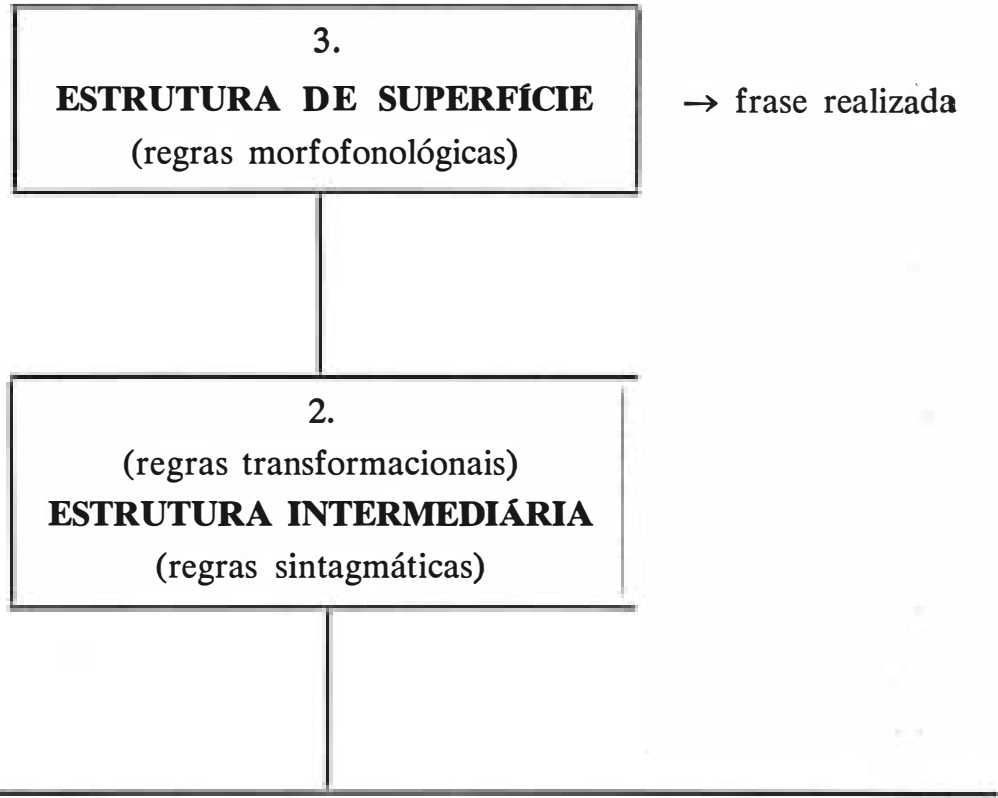

1.

Representações Semânticas

ESTRUTURA PROFUNDA

\begin{tabular}{|c|c|c|c|}
\hline $\begin{array}{l}\text { Padrão referencial- } \\
\text { semântico } \\
\text { (regr. form. lexical) }\end{array}$ & $\begin{array}{l}\text { Padrão lógico- } \\
\text { semântico } \\
\text { (regr. form. p/moda }\end{array}$ & & $\begin{array}{l}\text { Padrão sintático- } \\
\text { semântico } \\
\text { (regr. form. p/concat.) }\end{array}$ \\
\hline$\left\{\begin{array}{l}-\begin{array}{l}\text { Definições } \\
\text { externas } \\
- \\
\text { Definições } \\
\text { internas }\end{array}\end{array}\right.$ & — Predicadores & $\left\{\begin{array}{l}- \\
- \\
- \\
-\end{array}\right.$ & $\begin{array}{l}\text { Operador } L\left\{\begin{array}{l}- \text { Relações } \\
\text { casuais }\end{array}\right. \\
\text { Opercrit. } \\
\text { total } \\
\text { Operador } \\
\text { múltiplo- } \\
\text { parcial } \\
\text { Descr. } \\
\text { Atrib. }\end{array}$ \\
\hline
\end{tabular}




\section{Bibliografia consultada:}

Abraham, Samuel $e$ KiefFer Ferenc $-A$ theory of structural semantics. The Hague - Paris, Mouton, 1966.

Bellert, Irena - "Arguments and predicates in the logico-semantic structure of utterances". In F. Kiefer, editor, Studies in syntax and semantics. Dordrecht-Holland, D. Reidel Publishing Company, 1969, p. 34-54.

Bierwisch, Manfred - "Semantics". In John Lyons, editor, New horizons in linguistics. Middlesex (England), Penguin Books, 1972, p. 166-184.

BreKLE, Herbert - "Generative semantics vs. deep syntax". In F. Kiefer, editor, Studies in syntax and semantics. Dordrecht-Holland, D. Reidel Publishing Company, 1969, p. 80-90.

CARNAP, Rudolf - Meaning and necessity: a study in semantics and modal logic. Chicago, The University Chicago Press, 1956.

Сномsкy, Noam - Aspects de la théorie syntaxique. Trad. por Jean-Claude Milner. Paris, Editions du Seuil, 1971.

Сномsку, Noam - "Deep structure, surface structure and semantic interpretation". In Studies on semantics in generative grammar. The Hague Paris, Mouton, 1972, p. 62-119.

Church, Alonzo - "The need for abstract entities in semantic analysis". In Jerry Fodor e Jerrold Katz, editors, The structure of language: readings in the philosophy of language. New Jersey, Prentice-Hall, 1964, p. 437-445.

Fillmore, Charles - "Toward a modern theory of case". The Ohio State University project in linguistic analysis, Report no 13, 1966, p. 1-24.

Fillmore, Charles - "The case for case". In Emmon Bach e Robert Harms, org., Universals in linguistic theory. New York, Holt, Rinehart and Winston, 1968, p. 1-88.

Fillmore, Charles - "Types of lexical information". In F. Kiefer, editor, Studies in syntax and semantics. Dordrecht-Holland, D. Reidel Publishing Company, 1969, p. 109-137.

Fillmore, Charles - "Some problems for case grammar". In Monograph Series on Languages and Linguistics, no 24, 1971, p. 35-56.

Galmiche, Michel - La sémantique générative. Paris, Larousse, 1975.

KATZ, Jerrold \& FoDOR, Jerry - "The structure of a semantic theory". Language, 39 (2) : 170-210, 1963.

KubiK, $M$. - "A propos de la problématique de la structure profonde de la phrase". Linguistics: an international review, The Hague - Paris, Mouton, n. 83: 19-30, maio/1972.

LAKOFF, George - "Sobre la semántica generativa (1969-1971)". In Víctor Sánchez de Zavala, compilador, Semántica y sintaxis en la lingüistica transformatoria, I. Madrid, Alianza Editorial (1974), p. 335-443. 
LEECH, Geoffrey - Towards a semantic description of English. London: Longmans, 1969.

LeEch, Geofrey - Semantics. Middlesex (England), Penguin Books, 1974.

Maclay, Howard - “Overview”. In Steinberg, org., Semantics, Cambridge, 1971.

McCAwley, James - "The role of semantics in a grammar". In Emmon Bach e Robert Harms, editors, Universals in linguistic theory. New York, Holt, Rinehart and Winston, 1968, p. 124-169.

NiÉGER, Monique - "La notion de cas dans la théorie de Fillmore". In Problèmes de sémantique (en collaboration), Montréal, Les Presses de L'Université du Québec, 1973, p. 39-49.

Nilsen, Don Lee Fred - Toward a semantic specification of deep case. The Hague - Paris, Mouton, 1972.

Paillet, Jean-Pierre - "Prérequis pour l'analyse sémantique". In Problèmes de sémantique (en collaboration), Montréal, Les Presses de l'Université du Québec, 1973, p. 1-18.

Poldauf, Ivan - "Case in Contemporary English". Philologica Pragensia, Praga, Ceskoslovenská akademie vèd, n. 3: 121-131, 1970.

SGALl, Petr - "Topic, focus, and the ordering of elements of semantic representation". Philologica pragensia, Praga, Ceskoslovenská akademie vèd, n. 1: 1-14, 1972.

SOUthworth, Franklin - "A model of semantic srtucture". Language, 43(1): 342-361, 1967. 